\title{
INDICADOR E AVALIAÇÃO DA VULNERABILIDADE SOCIOAMBIENTAL NO MUNICIPIO DE SÃO PAULO ${ }^{1}$
}

\author{
Carolina Gamba* \\ Wagner Costa Ribeiro**
}

\section{RESUMO}

Este trabalho apresenta uma análise multidimensional da vulnerabilidade do município de São Paulo frente a processos relacionados a eventos extremos de precipitação, sobretudo escorregamentos de vertentes. Ele indica a estreita relação entre vulnerabilidade social e infraestrutural com áreas mais suscetíveis a este tipo de fenômeno, situação que caracteriza a segregação urbana. Para tal, faz-se uso de indicadores socioambientais elaborados a partir de dados secundários, obtidos junto ao IBGE e à Prefeitura do Município de São Paulo, que foram integrados e inseridos num Sistema de Informação Geográfica. O resultado aponta diferentes níveis de vulnerabilidade socioambiental entre os distritos do município frente ao processo de movimentação de terra.

Palavras-chave: Risco, vulnerabilidade, São Paulo (município), indicadores socioambientais, mudança do clima.

\section{Environmental assessment of vulnerability in São Paulo}

\section{ABSTRACT}

This work seeks to achieve a multidimensional analysis of the vulnerability of São Paulo City against processes related to extreme precipitation events, especially landslides. Intends to show the close relationship between social and infrastructural vulnerability, and areas more susceptible to this type of phenomenon, a situation that characterizes urban segregation. To this end, makes use of social and environmental indicators, based on secondary data, obtained from the IBGE and the Municipality of São Paulo. They were integrated and inserted in a Geographical Information System, in order to point out different levels of social-environmental vulnerability among districts of the city facing processes related to landslides.

Keywords: Risk, vulnerability, São Paulo City, social-environmental indicators, climate change.

\section{Introdução}

Este trabalho discute a vulnerabilidade urbana em sua multidimensionalidade, ou seja, pela conjugação de fatores sociais, econômicos e ambientais. Especificamente, busca contribuir para a avaliação das diferenças socioambientais no município de São Paulo no tocante à vulnerabilidade ao escorregamento. Pretende apontar a estreita relação entre vulnerabilidade social e infraestrutural com as áreas mais suscetíveis a este tipo de fenômeno, situação que caracteriza a segregação urbana. Foram usados dados secundários do IBGE e do município de São Paulo que, combinados, permitiram elaborar um indicador que expresse a relação entre 
vulnerabilidade e risco a escorregamento em São Paulo.

Além disso, haja vista que os eventos extremos de precipitação podem tornar-se mais frequentes e intensos na região, segundo os cenários traçados pelo Painel Intergovernamental sobre Mudança do Clima (IPCC, 2007) - em que pese todas as incertezas científicas sobre o tema; e de conhecimento que o ambiente urbano induz mudanças importantes no microclima local, este texto pauta-se no Princípio da Precaução. Com base nesse princípio, deve-se adotar medidas preventivas quando uma atividade ameaça a saúde humana ou o meio ambiente, ainda que suas causas e efeitos não tenham sido totalmente explicitadas pela ciência (DERANI, 2008). A expectativa é que esse trabalho possa colaborar na direção da tomada de ações preventivas de modo a diminuir os impactos socioambientais do escorregamento de vertentes.

O texto associa a discussão do tema da vulnerabilidade socioambiental (RIBEIRO, 2010) com a questão da adaptação a eventos extremos de precipitação prevista nas políticas de mudanças do clima nacional, estadual e municipal. O conceito de adaptação é entendido como o ajuste nos sistemas naturais e humanos em resposta aos estímulos ou efeitos climáticos atuais ou esperados, que ajude a moderar os prejuízos ou a explorar oportunidades benéficas (IPCC, 2007).

Para indicar a relação entre vulnerabilidade social e escorregamento no município de São Paulo, esse artigo está dividido em quatro partes. $\mathrm{Na}$ primeira discute o risco em suas múltiplas dimensões, inclusive geográfica para o caso de São Paulo. A seguir, apresenta o índice de vulnerabilidade socioambiental ao processo de escorregamento, que combinou aspectos sociais, de infra-estrutura e ambientais. Depois, são apresentados os resultados obtidos, com destaque para o mapa de Vulnerabilidade Socioambiental ao Risco de Escorregamento e Áreas de Risco, e, por fim, as considerações finais, que reforçam que o social predomina sobre o ambiental na determinação dos riscos a escorregamento em São Paulo.

\section{RISCO E DESIGUALDADE SOCIOAMBIENTAL EM SÃO PAULO}

Os riscos socioambientais constituem cada vez mais objeto de debates, haja vista o aumento do número de ocorrência e da intensidade de eventos extremos de diversas ordens. No tocante ao risco relacionado ao processo de escorregamento de encostas, muitos exemplos ocorridos nos últimos anos no Brasil podem ser citados. Verdadeiras tragédias que, a despeito do histórico de situações passadas que ocasionaram grandes prejuízos e perda de vidas humanas, continuam a se repetir, sobretudo a cada estação chuvosa.

Em termos conceituais, de acordo com o Ministério das Cidades (2006) o nível de risco é determinado pela probabilidade da ocorrência de um perigo natural, com consequências que variam em função da vulnerabilidade, que pode ser alterada pelo grau de gerenciamento. Esse conceito vai muito de aspectos objetivos (ZANIRATO et al., 2008). Há que se pensar nos fatores subjetivos, voltados à percepção (SLOVIC, 2010). Em concordância com Veyret (2007), o risco depende intrinsecamente do contexto histórico que o produziu, de suas relações com o espaço geográfico, dos modos de ocupação do território e das relações sociais tecidas em cada área e época.

Ainda que grande parte dos discursos procure justificar a ocorrência de crises com ênfase apenas nos condicionantes naturais, ou como conseqüência inevitável do "progresso", cada vez mais se tem claro que a configuração da Sociedade de Risco (BECK, 1992) relaciona-se ao processo amplo de expansão e modernização do capitalismo que, com vistas à produção social de riquezas, tem gerado, em ritmo alarmante, riscos com características e proporções nunca antes imaginadas.

A Geografia tem muito a contribuir para a análise do risco e da vulnerabilidade socioambiental como indicam trabalhos de geógrafos como November (2001), Calvo (2001) e Ribeiro (2010 e 2008a e b). Primeiramente por sua preocupação histórica com as relações tecidas entre meio ambiente e sociedade (em que pese o fato de que neste trabalho não se coloca tal oposição). 
Além disso, pela diversidade de estudos acerca das dinâmicas socioambientais urbanas. Por sua vez, destacam-se as possibilidades referentes ao emprego de técnicas de geoprocessamento, que cada vez mais enriquecem os estudos socioambientais.

Multidisciplinar por essência, a ciência geográfica oferece muitos elementos teóricos à compreensão do risco e da vulnerabilidade, temas também intrinsecamente multidimensionais, que requerem uma análise integrada de múltiplos fatores e em distintas escalas geográficas.

Em grandes metrópoles, como São Paulo, a configuração de contextos de vulnerabilidade ocorre de maneira mais profunda (RIBEIRO, $2008 b)$, pela contradição entre espaços integrados e desintegrados ao capitalismo mundial (CARLOS, 2006), resultantes de um desenvolvimento incrivelmente desigual. Tal desigualdade social é reflete. sobretudo, na intensa segregação urbana.

Verifica-se na produção do espaço urbano brasileiro uma simbiose entre padrões modernistas de construção e ocupação do solo (leis de zoneamento, código de obras, leis de parcelamento do solo) e o gigantesco crescimento da cidade ilegal, onde a contravenção é regra (MARICATO, 2003, p.153). Grostein (2001) também ressalta esta dualidade. De um lado a cidade formal, que concentra os investimentos públicos e, de outro, a cidade informal que cresce rapidamente na ilegalidade e na precariedade, de forma a contribuir para a formação de espaços urbanos sem atributos de urbanidade. Essas interpretações dialogam muito bem com as ideias da justiça ambiental, nesse caso aplicada à escala urbana. Autores como Herculano, Porto e Freitas (2000), Acselrad, Mello e Bezerra (2009), Valencio et al (2009), Acselrad (2010) e Moreno Jímenez (2010) contribuem na definição de um escopo teórico que permite vislumbrar a segregação como resultado de processos sociais que refletem no ambiente. O social determina o ambiental e não o contrário.

Uma das principais questões urbanas centra-se no funcionamento do mercado imobiliário. A valorização das terras e das edificações, devido à escassez decorrente do grande contingente populacional, mas, sobretudo pela forte especulação, relega o acesso ao mercado formal a apenas uma parcela da sociedade. Isto tem levado a uma grande concentração fundiária urbana (CARLOS, 2001), identificada na paisagem sob a forma de imensos vazios, com vistas à valorização.

Excluídas do mercado imobiliário formal, a população de baixa renda acaba por ocupar regiões desvalorizadas pelo mercado privado, bem como áreas públicas. Em sua maior parte está sujeita a diferentes tipos de risco - fundos de vale, sujeitos a inundações; encostas de morros, com grande risco de escorregamento; regiões poluídas e/ou áreas de proteção ambiental. Sem alternativas, constitui grandes aglomerações de habitações precárias, com o mínimo de infraestrutura.

Salienta-se que boa parte dos assentamentos de baixa renda caracterizados como invasões, na verdade, funciona por meio de um mercado imobiliário invisível, o que constitui para Davis (2006) a privatização das invasões. Tal fato amplia ainda mais as dificuldades da população marginalizada, que compra com muito esforço terrenos de empresários que atuam na ilegalidade e ofertam terrenos alheios sem respeitar as leis de zoneamento ou padrões de fornecimento de serviços.

Contudo, é preciso destacar que esta dualidade entre formal e informal perpassa toda a sociedade urbana, inclusive o Estado. As instituições públicas tornam-se mais ou menos permissivas em diferentes situações. Os governos, em geral, buscam garantir o desenvolvimento do ciclo do capital e, assim, criam a infraestrutura necessária à sua reprodução. Utilizam o espaço como elemento de dominação (CARLOS, 2001), alterando a legislação de acordo com interesses específicos.

Para Carlos (2001), a renovação urbana, por exemplo, verificada em muitas cidades brasileiras, constitui uma estratégia de dominação, em associação com diferentes setores econômicos. Tal aliança revela tanto a imposição do mercado imobiliário quanto as transformações recentes do capitalismo: a entrada do setor da construção civil no circuito industrial moderno e o desenvolvimento tecnológico em função dos novos padrões de realização da atividade econômica nas cidades 
mundiais.

Assim, percebe-se que o problema não está necessariamente na ausência ou na inadequação da legislação, mas em sua aplicação arbitrária. Existem instrumentos que visam à incorporação da cidade informal à formal. Porém, percebe-se que, se o direito à ocupação é aparentemente reconhecido, o mesmo não acontece com o direito à cidade (Grostein, 2001, p.17). As populações de baixa renda esperam do Estado uma resposta à crise habitacional urbana. Lutam pelo acesso à terra e, posteriormente, pela instalação de infra-estrutura adequada, ainda que em áreas de risco.

Verifica-se, portanto, que as causas da intensificação do processo de favelização da cidade vão além da discussão sobre a capacidade do poder público no sentido de reduzir a vulnerabilidade socioambiental, entendendo este conceito como a diminuição da capacidade de grupos e indivíduos para oferecer respostas e adaptarem-se diante de situações que envolvem risco, como eventos de precipitação pluviométrica intensa.

A questão da habitação no município de São Paulo não constitui novidade. Estima-se a existência de 889.808 domicílios precários no município, entre favelas, loteamentos, núcleos urbanizados, cortiços e conjuntos habitacionais (SÃO PAULO, 2010). O déficit atual da habitação no município é estimado em 227 mil domicílios, entre precários e coabitação indesejada. Além disso, a demanda projetada está entre 238 mil e 260 mil domicílios para famílias com renda até três salários mínimos, ou seja, uma média de 465 mil a 487 mil novos domicílios serão necessários até 2024. No total são 840 mil novas unidades, se outras faixas de renda forem consideradas.

Ainda que existam diferentes programas habitacionais em vigência no município, que atendem a demandas específicas da população, como o Programa de Urbanização e Regularização de Assentamentos Precários, o Mananciais, o Requalificação de Cortiços, o Requalificação de Moradias, o de Subsídios ao Aluguel e o Parceria Social, estima-se que sejam necessários cerca de $\mathrm{R} \$ 58,00$ bilhões para a realização dos mesmos durante o período 2009-2024 (SÃ̃O PAULO, 2010, p.17).

Além disso, no que tange aos recursos fundiários, são precisos mais de 38 milhões de $\mathrm{m}^{2}$ (média de $50 \mathrm{~m}^{2}$ por unidade habitacional), o que se revela desafiador, pois será preciso, além das novas políticas referentes à ocupação de terrenos e prédios no centro, rever a legislação atual para atender a esta demanda habitacional gigantesca, de forma a gerar o menor impacto ambiental possível e a impedir a ocupação de áreas de risco

\section{Domicílios segundo o tipo de assentamento por região na cidade de São Paulo (adaptado de SÃo PAULO, 2010)}

Durante décadas, sem levar em consideração as características do meio físico, o processo de ocupação das regiões periféricas da cidade foi realizado, sobretudo, pela terraplanagem de terrenos ou cortes e aterros para a criação de lotes, de forma a engendrar diversas situações de risco ao processo de escorregamento. Os escorregamentos ou deslizamentos são aqui entendidos como conceitos genéricos que abrangem diversos processos específicos de movimentos de massa, gerados pela ação da gravidade em terrenos inclinados e deflagrados, sobretudo, por chuvas moderadas ou fortes de longa duração que se infiltram e saturam o solo e levam a situações de instabilidade do terreno (BRASIL, 2007).

Seria incorreto fazer generalizações no sentido de que somente grupos socioeconômicos menos favorecidos são afetados por tais ventos. Mas é sabido que, para boa parte da população de baixa renda, habitar áreas de risco ao processo de escorregamento é a única alternativa possível. $E$, quando da ocorrência de eventos extremos de precipitação, mostram-se ainda mais vulneráveis, pela falta de infraestrutura adequada, pelo baixo padrão construtivo das moradias, pela dificuldade de constituir um novo patrimônio caso haja perdas materiais significativas, entre outras dificuldades.

Diante desta realidade socioambiental tão heterogênea e desigual, ressalta-se, mais do que nunca, a importância da reflexão acerca do modelo de desenvolvimento que configura tantos contextos vulneráveis. Especificamente, destaca-se a centralidade do planejamento urbano com vistas à redução da vulnerabilidade social e ambiental na cidade, de forma integrada e preventiva. 


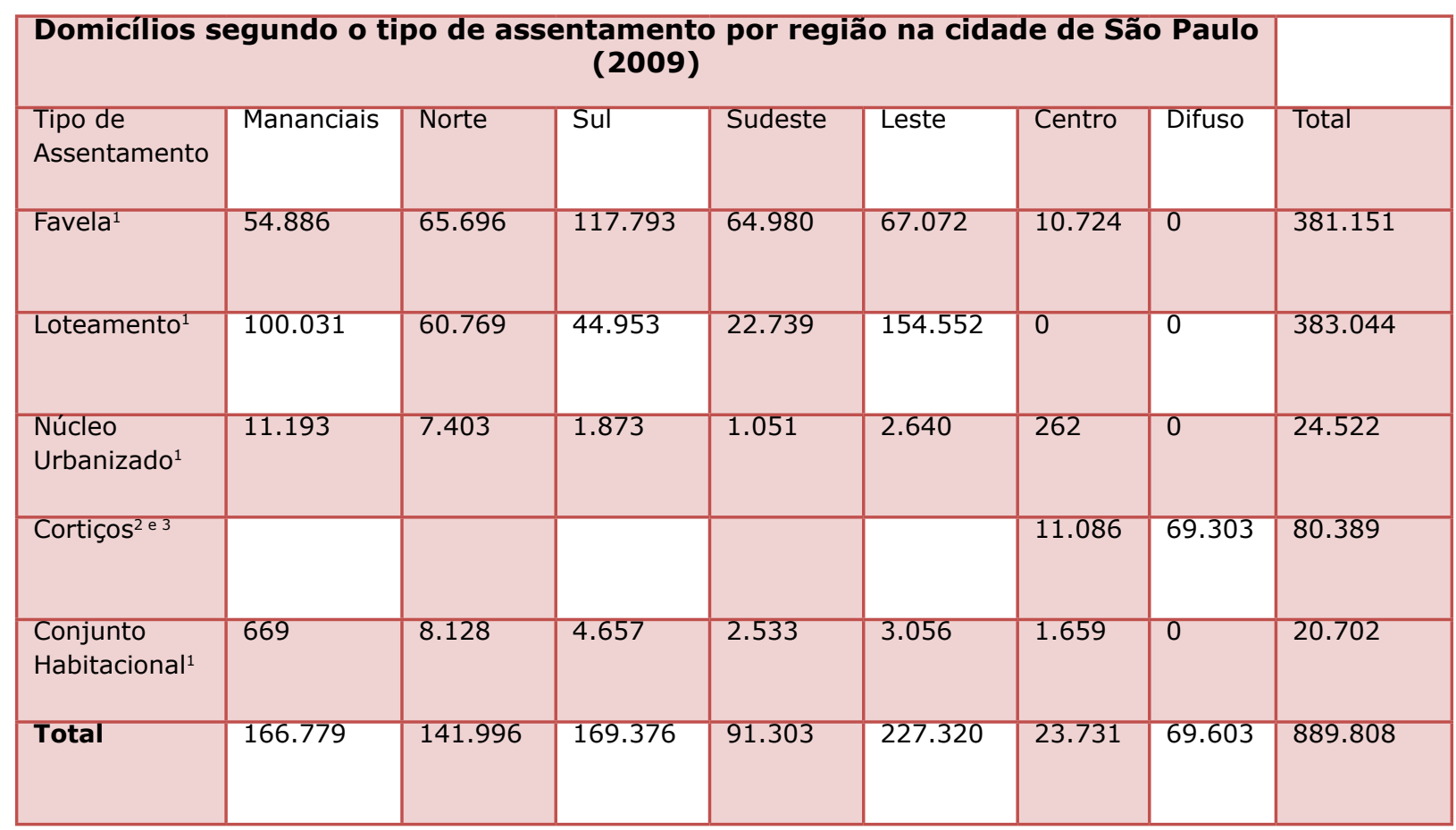

Fonte: (1) Habisp, fevereiro de 2010, referente às subprefeituras Sé e Mooca; (2) dado obtido a partir do número levantado pela Fundação Seade, do qual foi subtraído o levantamento do Habisp para as subprefeituras Sé e Mooca; (3) o valor total de 80.389 domicílios encortiçados é estimado pela Fundação Seade.

No que tange à atuação da Defesa Civil no município frente à gestão de processos relacionados a escorregamentos, verifica-se o reconhecimento crescente da importância da participação ativa das comunidades habitantes de áreas de risco, via Núcleos de Defesa Civil (NUDECs). Ressalta-se, também, a importância dos Planos Preventivos de Defesa Civil (PPDC) desenvolvidos, sobretudo, durante a estação chuvosa. Contudo, tais iniciativas ainda estão muito aquém das necessidades reais da sociedade.

Em vista de toda esta complexidade, obviamente qualquer medida no tocante aos riscos que envolvem escorregamentos deve ser resultado de estudos detalhados, estes que, por sua vez, requerem necessariamente sistemas de informações confiáveis, que captem tanto as especificidades de cada área como também possibilitem o entendimento dos processos em escalas geográficas mais abrangentes, como a regional, a nacional e mesmo global.

\section{Índice de vulnerabilidade socioambiental ao processo de escorregamento.}

Para chegar-se ao índice de vulnerabilidade socioambiental ao processo de escorregamento utilizaram-se linguagens quantitativas, qualitativas e de geoprocessamento, que geraram indicadores de infraestrutura, sociais e ambientais que, ao serem agregados, apontam a espacialização da vulnerabilidade socioambiental do município de São Paulo ao processo de escorregamento.

Primeiramente, foi feita a seleção das variáveis a serem utilizadas. Tal escolha, a princípio, pautou-se na necessidade da utilização de bancos de dados que dispusessem de informações para o conjunto dos municípios brasileiros, uma vez que se pretende que o indicador desenvolvido possa 
ser utilizado em outras localidades.

Optou-se pelas informações do Censo Demográfico 2000, desenvolvido pelo Instituto Brasileiro de Geografia e Estatística (IBGE), haja vista que o Censo Demográfico de 2010 estava em processo de conclusão no período de desenvolvimento desta pesquisa. Ao longo do processo de criação do indicador viu-se a necessidade de utilização de algumas variáveis disponibilizadas apenas pela Prefeitura Municipal de São Paulo - uma da dimensão social e todas as variáveis ambientais.

No tocante à escala geográfica, uma vez definido como área de estudo o município de São Paulo em sua totalidade e, na ausência das informações ambientais necessárias na escala dos setores censitários, optou-se pela escala dos distritos administrativos, que se mostrou adequada aos objetivos propostos.

Neste trabalho procurou-se integrar variáveis infraestruturais, sociais e ambientais para a construção de um único indicador socioambiental representativo para indicar os distritos paulistanos mais vulneráveis ao processo de escorregamento, bem como identificar quais as combinações de fatores que configuram tais contextos.

Em relação à infraestrutura, foram escolhidos indicadores relacionados à oferta de serviços básicos de saneamento à população abastecimento de água, rede de esgotamento e coleta de lixo. Entende-se que os mesmos são determinantes da qualidade socioambiental da população.

Além disso, sua insuficiência/inadequação também pode contribuir para o agravamento da vulnerabilidade relacionada ao processo de escorregamento. Ligações mal feitas da rede de abastecimento de água e de esgoto podem resultar em vazamentos e infiltrações no solo que induzem escorregamento de vertentes, que muitas vezes resultam em danos materiais e sociais significativos. Por sua vez, a destinação inadequada do lixo em áreas íngremes também aumenta a instabilidade do solo e, na ocorrência de eventos extremos de precipitação, amplia o risco de deslizamentos.

A seleção dos indicadores sociais rendimento, anos de estudo e população residente em favelas - pautou-se na necessidade de identificar quais porções do território paulistano oferecem menor capacidade de resposta diante de situações extremas, como em eventos de precipitação pluviométrica intensa. Ainda que existam muitos fatores que determinam a vulnerabilidade socioambiental, há evidentemente uma grande relação entre vulnerabilidade e pobreza.

Além disso, destaca-se a importância do elemento cultural-educativo no sentido da informação sobre o risco. A escolha do indicador anos de estudo deve-se ao fato de que, em teoria, o maior grau de escolaridade está diretamente associado a um conhecimento maior sobre os riscos (escorregamentos e inundações). Ressaltase, porém que isto não constitui regra, uma vez que as áreas de risco são também habitadas por populações bastante escolarizadas. Mas sabe-se que estes grupos podem escolher outros locais para viver, enquanto a grande maioria dos moradores das áreas de risco não possui alternativa. Por meio de tais indicadores procurou-se observar a segregação socioambiental no município.

No tocante aos indicadores ambientais, pensou-se em elementos que fossem importantes para caracterizar contextos vulneráveis relacionados ao processo de escorregamento. De acordo com as informações disponíveis, escolheu-se vegetação, temperatura e declividade. A ausência ou pouca vegetação nos centros urbanos e a impermeabilização do solo, associada à poluição do ar na metrópole, contribui para o aumento da temperatura e a redução da umidade relativa do ar, de forma a produzir as chamadas ilhas de calor (LOMBARDO, 1985). Por sua vez, a alta temperatura provoca maior formação de 
nebulosidades e precipitações intensas, que podem provocar inundações, alagamentos e escorregamentos. O indicador declividade, evidentemente, relaciona-se de maneira direta com a ocorrência de escorregamentos, sobretudo em áreas alteradas pela ocupação humana, de modo a aumentar a instabilidade do terreno.

No sentido da tornar tais variáveis comparáveis, bem como para facilitar a agregação das informações, optou-se pelo cálculo de índices para cada uma delas. A construção destes índices teve como base os critérios utilizados por Morato (2008), bastante semelhantes ao cálculo do Índice de Desenvolvimento Humano (IDH). O valor de cada índice é igual ao quociente entre: a diferença entre o valor observado em cada distrito e o valor mínimo possível; e a diferença entre os limites máximos (ou de referência) e mínimos possíveis.

Após a obtenção dos índices para todas as nove variáveis, partiu-se para geração de três índices sintéticos: Índice de Vulnerabilidade Infraestrutural, Índice de Vulnerabilidade Social e Índice de Vulnerabilidade Ambiental. Estes resultam da média simples das três variáveis que compõem cada uma destas dimensões.

Pela observação dos índices básicos de cada variável, a partir dos valores apresentados pelos distritos nos índices sintéticos, foram definidas cinco classes de vulnerabilidade, cujos intervalos variam ligeiramente conforme o indicador analisado:

- Vulnerabilidade muito baixa/baixíssima: todas as variáveis analisadas apresentam as melhores condições entre os distritos (ou em relação ao valor de referência);

- Vulnerabilidade baixa: a maior parte das variáveis apresenta boas condições entre os distritos (ou em relação ao valor de referência);
- Vulnerabilidade média: a maior parte das variáveis apresenta condição intermediária entre os distritos (ou em relação ao valor de referência);

- Vulnerabilidade alta: a maior parte das variáveis aponta condições ruins em relação aos demais distritos (ou ao valor de referência);

- Vulnerabilidade muito alta: todas as variáveis apresentam péssimas condições entre os distritos (ou ao valor de referência).

Após a obtenção dos três índices sintéticos específicos de vulnerabilidade, partiu-se para a elaboração do índice sintético final, o Índice de Vulnerabilidade Socioambiental ao Processo de Escorregamento. Da mesma forma que os índices sintéticos de vulnerabilidade social, infraestrutural e ambiental foram gerados, este o indicador resulta da média entre os três índices específicos. O quadro abaixo mostra a estrutura do processo de obtenção dos indicadores.

Terminada a etapa de efetuação dos cálculos, todos os índices básicos de cada variável, os três índices sintéticos específicos de vulnerabilidade (infraestrutural, social e ambiental) e o Índice de Vulnerabilidade Socioambiental ao Processo de Escorregamento foram mapeados com vistas a facilitar a comparação entre os distritos.

Também foram mapeadas as áreas sujeitas a escorregamentos e a processos erosivos identificadas pelo Instituto de Pesquisas Tecnológicas em 2010, em contrato com a Prefeitura Municipal de São Paulo. As mesmas correspondem a cerca de $13,5 \mathrm{Km}^{2}(0,9 \%$ da área total do município). A intenção do georreferenciamento destas áreas de risco foi realizar a associação dos pontos mapeados com o mapa final obtido, no sentido de verificar a adequação da metodologia utilizada. 


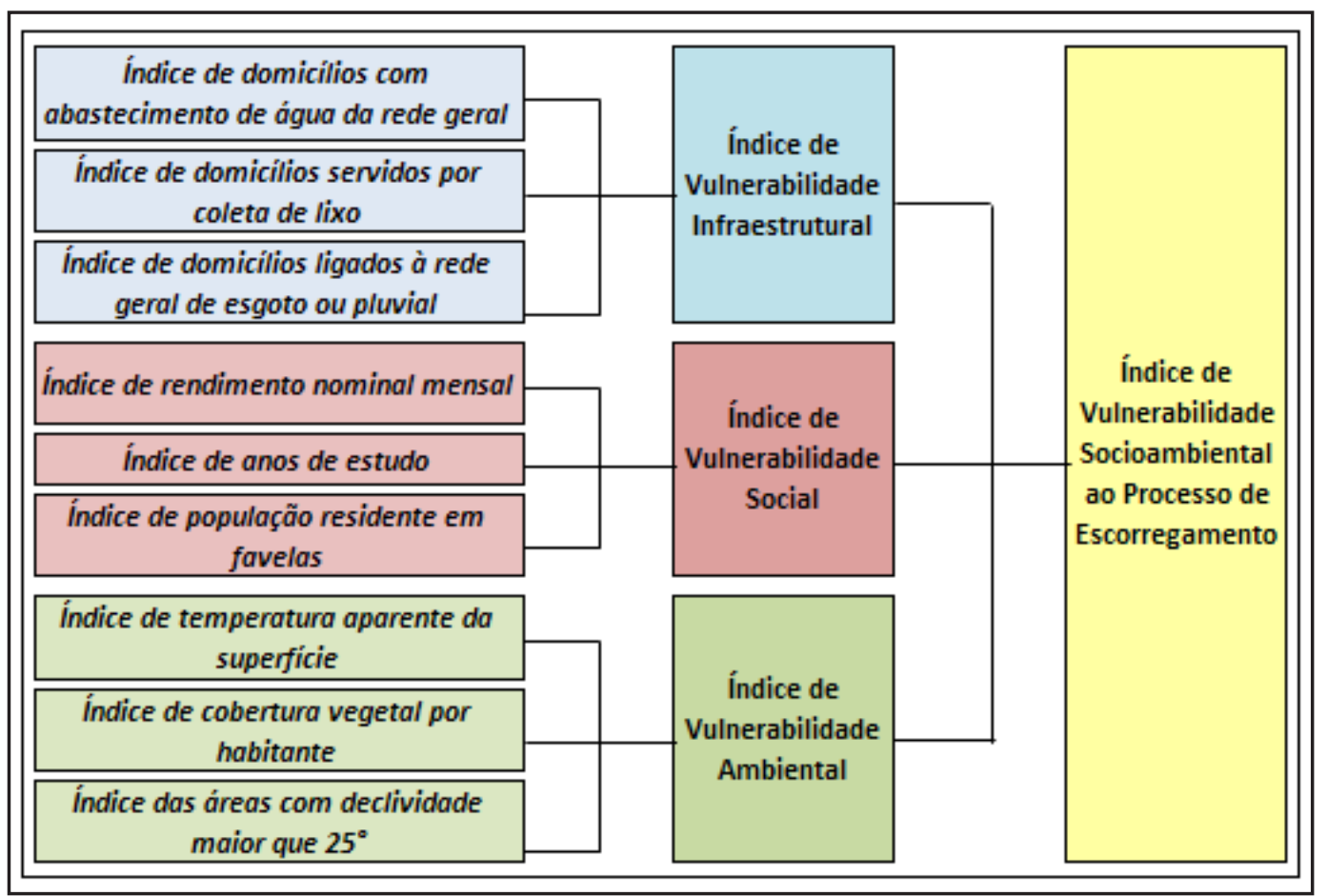

Estrutura da obtenção dos índices sintéticos (GAMBA, 2011)

\section{RESULTADOS ALCANÇADOS}

O Índice de Vulnerabilidade Socioambiental ao Processo de Escorregamento resulta da média entre o Índice de Vulnerabilidade Infraestrutural, do Índice de Vulnerabilidade Social e do Índice de Vulnerabilidade Ambiental.

Como pode ser observado a seguir, verifica-se grande heterogeneidade socioambiental entre os distritos do município de São Paulo quando se agregam as nove variáveis. Ainda que 39 distritos apresentem baixa vulnerabilidade socioambiental, outros 32 apresentam vulnerabilidade alta, ou muito alta.

Por meio do mapeamento deste índice sintético final foi possível perceber que tais disparidades mostram claramente a existência de intensa segregação socioambiental na cidade. Verifica-se uma grande mancha urbana na porção central, referente aos distritos que detém os melhores índices de vulnerabilidade socioambiental ao processo de escorregamento. Ainda que a boa parte deles apresente baixos índices de vulnerabilidade ambiental (sobretudo por conta dos indicadores de vegetação e temperatura), os bons resultados infraestruturais e socioeconômicos obtidos indicam que possuem maior capacidade para oferecer respostas diante de eventos extremos de precipitação.

Alguns distritos da Zona Norte - (Santana, Tucuruvi e Mandaqui) e da Zona Leste (Tatuapé e José Bonifácio) também apresentam bons índices, em todas as variáveis analisadas.

Inversamente, verifica-se que muitas áreas de baixa vulnerabilidade ambiental apresentam péssimas condições socioeconômicas e infraestruturais, que acabam por configurar contextos de alta vulnerabilidade. Isto pode ser verificado em quase todos os distritos da Zona Sul (Marsilac, Parelheiros, Grajaú, Pedreira, Jardim Ângela, Cidade Dutra); na Zona Leste (Iguatemi, Cidade Tiradentes, Cangaíba) e na Zona Norte (Anhanguera, Perus, Jaraguá e Cachoeirinha). 


\section{ÍNDICE DE VULNERABILIDADE SOCIOAMBIENTAL AO RISCO DE ESCORREGAMENTO E ÁREAS DE RISCO}

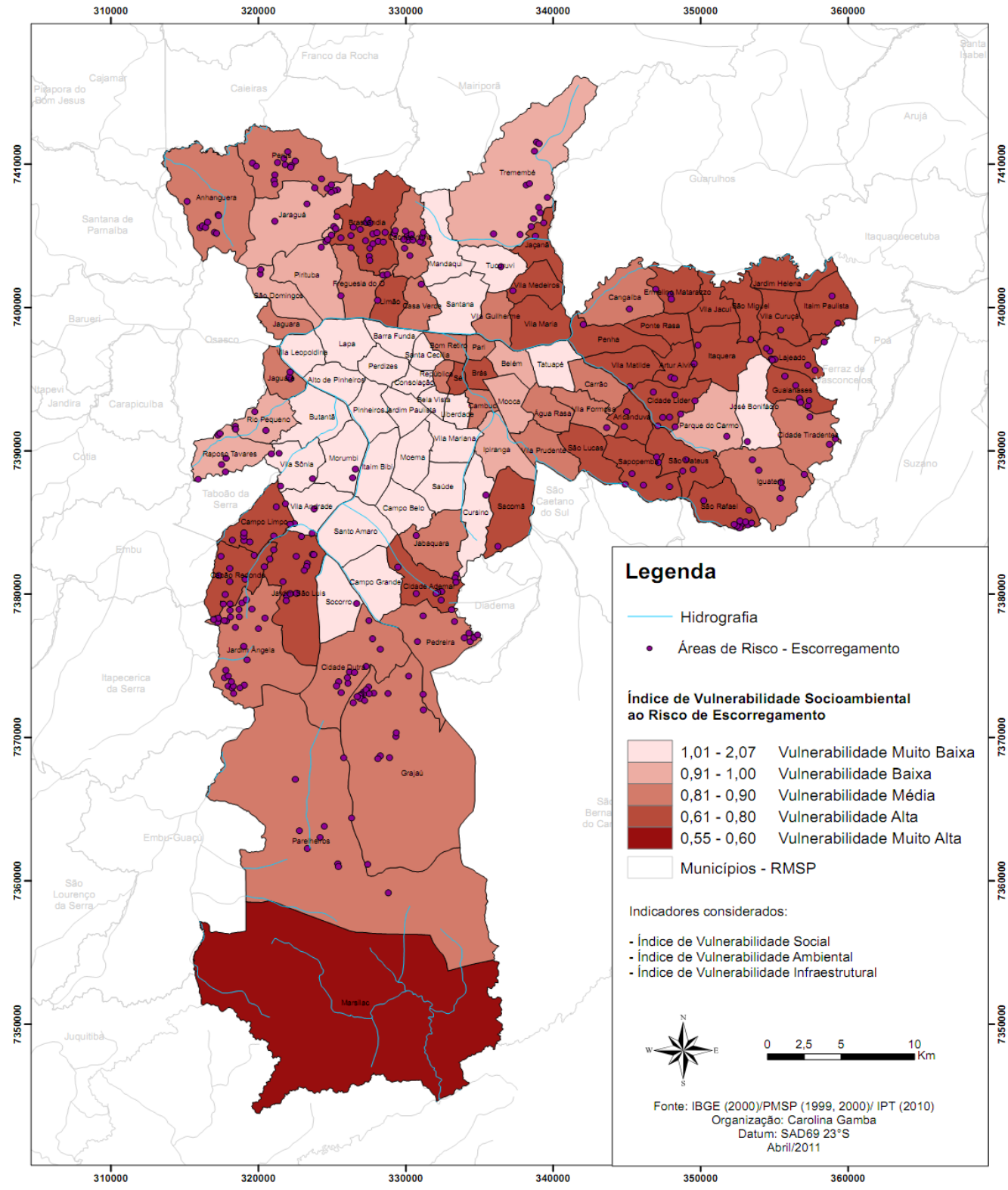

Mapa 24 - Índice de Vulnerabilidade Socioambiental ao Risco de Escorregamento e Áreas de Risco - Distritos do Município de São Paulo (IBGE, 2000; PMSP, 1999, 2000; IPT, 2010 / Organização: Carolina Gamba, 2011) 
Observa-se que a maioria dos distritos da Zona Leste se encontra em situação de alta vulnerabilidade socioambiental ao risco de escorregamento, sobretudo pela fragilidade das condições socioeconômicas, associadas a contextos de média e alta vulnerabilidade ambiental.

Outra porção do território paulistano bastante vulnerável envolve os distritos de Campo Limpo, Capão Redondo e Jardim São Luis, que apresentam índices de vulnerabilidade ambiental médio a alto e constituem áreas extremamente vulneráveis do ponto de vista social, com grande parte de sua população residente em favelas.

Na Zona Norte, os distritos de Brasilândia (média vulnerabilidade ambiental e alta vulnerabilidade social); Limão, Vila Medeiros, Vila Guilherme e Jaçanã (média vulnerabilidade social e alta vulnerabilidade ambiental) apresentaram os piores índices. No Centro, os distritos Sé e Brás detêm baixos indicadores, sobretudo pelo alto índice de vulnerabilidade ambiental obtido (pouquíssima vegetação e temperaturas bastante elevadas).

De maneira geral, verifica-se que no tocante à avaliação da vulnerabilidade socioambiental ao processo de escorregamento, as variáveis sociais mostraram-se determinantes para apontar as áreas que apresentam contextos mais frágeis, haja vista que se verificam grandes porções do território que apresentaram baixo índice final, mesmo em distritos com porcentagem mínima de terrenos com declividade maior que $25^{\circ}$.

Entende-se que as condições de ocupação dos terrenos e o padrão construtivo das moradias são fundamentais para compreender a ocorrência de escorregamentos em distritos com índice de vulnerabilidade ambiental baixo.

Ressalta-se que a escala dos distritos não oferece o detalhamento necessário para verificar todo o conjunto de fatores que caracteriza a ocorrência deste tipo de processo. Contudo, a intenção aqui é fazer a associação entre elementos naturais e sociais e verificar quais distritos possuem menor capacidade de resposta diante de eventos extremos, ou seja, configuram contextos socioambientais mais vulneráveis.

Com o georreferenciamento das áreas de risco referentes ao processo de escorregamento, levantadas pelo Instituto de Pesquisas Tecnológicas (IPT) em 2010 e sua adição ao mapa da Vulnerabilidade Socioambiental do Município de São Paulo ao Processo de Escorregamento, foi possível demonstrar a adequação da metodologia utilizada. A camada (layer) dos pontos referentes às áreas de risco apresenta grande correlação com as áreas indicadas como de maior vulnerabilidade socioambiental ao processo de escorregamento.

Tais pontos distribuem-se por todo o "anel" de alta vulnerabilidade, observado na Zona Leste da cidade. Também se verifica grande número de áreas de risco na Zona Sul, sobretudo na região do Campo Limpo, Capão Redondo, Jardim São Luis e Jardim Ângela - distritos onde mais de $20 \%$ da população reside em favelas

$\mathrm{Na} Z$ Zona Norte, o distrito de Brasilândia apresenta cerca de 20 áreas de risco de escorregamento. O mesmo obteve índice médio de vulnerabilidade ambiental, mas caracteriza-se por uma alta vulnerabilidade ambiental, com mais de $20 \%$ de sua população residente em favelas.

No geral, percebe-se que a ocupação irregular, por meio da utilização de técnicas construtivas inadequadas são fatores essenciais para a compreensão da existência deste número significativo de áreas de risco de escorregamento no município de São Paulo, haja vista que a maior parte do território não apresenta grandes declividades. O processo de ocupação amplia a instabilidade de áreas íngremes, com a retirada da vegetação e a instalação de infraestrutura inadequada, de forma a aumentar o risco relacionado ao escorregamento, sobretudo em períodos mais chuvosos.

\section{CONSIDERAÇÕES FINAIS}

É fato que existem muitas incertezas no tocante às alterações no regime de chuvas, que não permitem o estabelecimento de cenários inequívocos, haja vista que muitos modelos apresentam diferenças significativas no tocante ao estudo de um único fenômeno ou região. Contudo, em que pese tais considerações, ressalta-se a importância do Princípio da Precaução, haja vista que as previsões de aumento de temperatura feitas pelo IPCC mostram-se cada vez mais confiáveis 
e, um clima mais quente implica em aumento na quantidade de vapor de água na atmosfera e, consequentemente, em uma aceleração do ciclo hidrológico.

Diante da grande vulnerabilidade social verificada no município de São Paulo e da intensa segregação socioambiental que leva as comunidades de menor renda a habitarem as periferias da cidade - muitas vezes em áreas sem infraestrutura adequada e em encostas inapropriadas à ocupação; a possibilidade do aumento da ocorrência e intensidade de eventos extremos de precipitação aumenta o alerta para a amplificação da vulnerabilidade socioambiental ao escorregamento na cidade.

Certamente não há como fazer generalizações no sentido de que somente as populações mais carentes do ponto de vista social e econômico são as únicas afetadas por tais eventos. Mas evidencia-se a existência de diferentes graus de vulnerabilidade. Entende-se que o fator socioeconômico tem um peso fundamental e central na determinação do grau de vulnerabilidade de um indivíduo ou grupo social frente a situações que envolvem risco ao escorregamento.

Isso porque a fragilidade socioeconômica é determinante na definição do processo de segregação urbana. Num município onde a mercadoria terra mostra-se cada vez mais valiosa, são muitos os que são compelidos a habitar áreas desvalorizadas pelo ciclo do capital. Encostas íngremes, naturalmente inapropriadas à moradia por conta de agentes predisponentes como a geologia, a geomorfologia e a hidrologia. Além disso, na maior parte dos casos, o processo de ocupação amplifica a possibilidade da ocorrência de escorregamentos, haja vista as alterações que desestabilizam ainda mais o terreno cortes, desmatamento, instalação precária de infraestrutura, entre outras.

Ressalta-se que analisar a vulnerabilidade ambiental ao escorregamento na cidade na escala geográfica dos distritos oferece limitações, porque as áreas de risco são pontuais e cada distrito possui distintas classes de declividade.

Entender as dinâmicas que levam à (re)produção de espaços de desigualdades é fundamental para a realização de análises sobre a vulnerabilidade socioambiental na metrópole, em seus diferentes níveis.

Os indicadores infraestruturais e sociais mostraram-se determinantes para apontar as áreas que apresentam contextos de maior fragilidade. Ou seja, não é possível explicar a existência da grande quantidade de áreas de risco ao processo de escorregamento no município sem levar em consideração os condicionantes de ordem social. As áreas que apresentam os piores índices sociais, referentes à renda, à escolaridade e à taxa de população residente em favelas relacionam-se aos distritos com maior número de áreas de risco (por exemplo, Jardim Ângela, Brasilândia e São Rafael).

Tal situação reflete a intensa segregação socioambiental urbana verificada na cidade. Entende-se que a forma de ocupação dos terrenos e de instalação de infraestrutura, bem como o padrão construtivo das moradias, são fundamentais à compreensão da existência de significativo número de áreas de escorregamento em áreas com declividade média a alta e índice de vulnerabilidade ambiental geral baixo. No indicador sintético final, os fatores sociais desempenharam grande papel.

Reforça-se mais uma vez a necessidade do gerenciamento deste processo no município em busca da redução das vulnerabilidades socioambientais específicas verificadas em distintas áreas da cidade. A construção de indicadores constitui um passo importante para a identificação, delimitação e mapeamento dos contextos vulneráveis.

Contudo, o conhecimento do risco e da vulnerabilidade socioambiental constitui apenas a primeira etapa. Ações estruturais e não estruturais são extremamente necessárias. Certamente o déficit habitacional do município não será resolvido a curto (nem médio) prazo. Mesmo com a existência de vários programas de moradia popular em andamento, a demanda é imensa, de difícil absorção. As soluções são caras e demoradas. Mas absolutamente essenciais.

Medidas de caráter paliativo fazem-se importantes, no sentido da comunicação do risco junto à população, bem como no treinamento simples para a evacuação das áreas de risco a eventos extremos de precipitação. Por outro 
lado, é fundamental a retirada da população dos locais que apresentam alto risco ao processo de escorregamento, o que requer bastante planejamento, haja vista que é necessário considerar os vínculos sociais, culturais e de trabalho que a população deslocada mantinha com o lugar onde vivia. Cada situação deve ser avaliada em toda sua particularidade.

É primordial a busca por soluções e a implementação de medidas que visem ao solucionamento de problemas antigos verificados na metrópole paulistana, que amplificam a vulnerabilidade socioambiental de grande parte de sua população, esta que oferece cada vez menor capacidade de resposta diante de situações adversas.

Com base no Princípio da Precaução, diversas políticas voltadas para a mudança do clima oferecem oportunidades no sentido da adaptação e da redução das vulnerabilidades locais. Independente das incertezas frente ao aumento do número e intensidade de eventos extremos de precipitação no município, representam mais uma possibilidade de resolução de problemas crônicos na cidade de melhoria das condições de vida de boa parte da população.

\section{Notas}

1. Trabalho desenvolvido com apoio do CNPq.

\section{Bibliografia}

ACSELRAD, Henri, MELLO, C e BEZERRA, G. O que é justiça ambiental. Rio de Janeiro : Garamond, 2009.

ACSELRAD, Henri. Ambientalização das lutas sociais - o caso do movimento por justiça ambiental. Estud. av. 2010, vol.24, n.68, pp. 103-119.

BECK, Ulrich. La sociedad del riesgo: hacia una nueva modernidad. Barcelona: Paidós, 1992, 393p.

BRASIL. Ministério das Cidades/Cities Alliance. Prevenção de Riscos de Deslizamentos em Encostas: Guia para Elaboração de Políticas Municipais. Brasília: Ministério das Cidades; Cities Alliance, 2006, 111p.

Ministério do Meio Ambiente. Vulnerabilidade Ambiental: Desastres naturais ou fenômenos induzidos? Brasília: MMA, 2007. 192p.

CALVO GARCÍA-TORNEL, Francisco. Sociedades y territorios en riesgo. Barcelona: Ediciones del Serbal, 2001.

CARLOS, Ana Fani Alessandri. "Dinâmicas urbanas na metrópole de São Paulo". In: ARROYO, Mónica; SILVEIRA, María Laura. América Latina: cidade, campo e turismo. São Paulo: CLASO, Consejo Latinoamericano de
Ciencias Sociales, dezembro de 2006, pp75-88. . "São Paulo hoje: as contradições no processo de reprodução do espaço". Scripta Nova Revista Electrónica de Geografía y Ciencias Sociales. Universidad de Barcelona, n.88, maio de 2001.

DAVIS, Mike. Planeta Favela. São Paulo: Boitempo, 2006. $272 \mathrm{p}$.

DERANI, Cristiane. Direito ambiental econômico. São Paulo: Saraiva, 2008, 297p.

GAMBA, Carolina. Avaliação da Vulnerabilidade Socioambiental dos Distritos do Município de São Paulo a Processo de Escorregamento. Dissertação de Mestrado - Programa de Pós-Graduação em Geografia Humana do Departamento de Geografia da Faculdade de Filosofia, Letras e Ciências Humanas da Universidade de São Paulo. São Paulo, 2011, 204p.

GROSTEIN, Marta. Dora. "Metrópole e Expansão Urbana". A persistência de processos insustentáveis. São Paulo em Perspectiva, 15 (1) 2001, pp. 13-19.

HERCULANO, Selene; PORTO, Marcelo Firpo S.; FREITAS, Carlos Machado (Orgs.). Qualidade de vida e riscos ambientais. Niterói: EdUFF, 2000. 
IPCC. "Summary for Policymakers". In: Climate Change 2007: Impacts, Adaptation and Vulnerability. Contribution of Working Group II to the Fourth Assessment Report of the Intergovernmental Panel on Climate Change. Cambridge University Press, 2007, pp.07-22.

IPT. "Mapeamento das Áreas de Risco", 2010. Disponível em: http://www3.prefeitura.sp.gov.br/ saffor_bueiros/FormsPublic/serv3AreasRisco.aspx

LOMBARDO, Magda Adelaide. Ilha de Calor Nas Metrópoles: Exemplo de São Paulo. São Paulo: HUCITEC, 1985. 210 p.

MARICATO, Ermínia. "Metrópole, legislação e desigualdade". São Paulo: Estudos Avançados 17 (48), 2003, pp.151-167.

MORATO, Rúbia Gomes. Análise Espacial e Desigualdade Ambiental no Município de São Paulo. Tese de Doutorado - Programa de Pós-Graduação em Geografia Humana do Departamento de Geografia da Faculdade de Filosofia, Letras e Ciências Humanas da Universidade de São Paulo. São Paulo, 2008, 154p.

MORENO JIMÉNEZ, Antonio. Justicia ambiental. Del concepto a la aplicación en análisis de políticas y planificación territoriales. Scripta Nova. Revista Electrónica de Geografía y Ciencias Sociales. [En línea]. Barcelona: Universidad de Barcelona, 1 de marzo de 2010, vol. XIV, no 316. <http://www.ub.es/geocrit/sn/sn-316.html>.

NOVEMBER, Valerie. Les territoires du risque: le risque comme objet de refléxion géographique. Berna: Lang, 2002 .

RIBEIRO, Wagner Costa. Políticas públicas ambientais no Brasil: mitigação das mudanças climáticas. Scripta Nova. Revista Electrónica de Geografía y Ciencias Sociales. Barcelona: Universidad de Barcelona, 1 de agosto de
2008 a, vol. XII, núm. 270 (25). <http:// www.ub.es/geocrit/sn/sn-270/sn-270-25.htm>.

RIBEIRO, Wagner Costa. Impactos das mudanças climáticas em cidades no Brasil. Parcerias Estratégicas, v. 27, p. 297-321, 2008 b.

RIBEIRO, Wagner Costa. Riscos e vulnerabilidade urbana no Brasil. Scripta Nova. Revista Electrónica de Geografía y Ciencias Sociales. [En línea]. Barcelona: Universidad de Barcelona, 1 de agosto de 2010, vol. XIV, no 331 (65). <http:// www.ub.es/geocrit/sn/sn-331/sn-331-65.htm> .

SÃo PAULO. Secretaria da Habitação. Plano Municipal da Habitação 2009 2024. São Paulo, setembro de 2010, 414p.

SLOVIC, Paul. The Psychology of risk. Saude soc. [online]. 2010, vol.19, n.4 [citado 2011-08-06], pp. 731-747. Disponível em: $<$ http://www.scielo.br/scielo.php?script $=$ sci_ arttext\&pid $=$ S0104-12902010000400002\&ln $\mathrm{g}=\mathrm{pt \& nrm}=\mathrm{iSO}>$. ISSN 0104-1290. http:// dx.doi.org/10.1590/S0104-12902010000400002.

VALENCIO, Norma, SIENA, Mariana, MARCHEZINI, Victor e GONÇALVES, Luciano Costa (Orgs.). Sociologia dos desastres: construção, interfaces e perspectivas no Brasil. São Carlos : RiMa Editora, 2009.

VEYRET, Yvette. (Org.). Os riscos: o homem como agressor e vítima do meio ambiente. São Paulo: Contexto, 2007, 320 .

ZANIRATO, Silvia Helena; RAMIRES, Jane Z. S.; AMICCI, Anie Gracie Noda; ZULIMAR, Márita Ribeiro; RIBEIRO, Wagner Costa. Sentidos do risco: interpretações teóricas. Biblio 3W, Revista Bibliográfica de Geografía y Ciencias Sociales, Universidad de Barcelona, Vol. XIII, no 785, 25 de mayo de 2008. <http://www.ub.es/geocrit/b3w-785.htm>. 